Supporting Information for

\title{
Redox Species-Based Electrolytes for Advanced Rechargeable
}

\section{Lithium-Ion Battery}

Jun Ming, ${ }^{\dagger *}$ Mengliu Li ${ }^{\dagger}$ Pushpendra Kumar, Ang-Yu Lu, Wandi Wahyudi, and Lain-Jong Li*

Physical Sciences and Engineering Division, King Abdullah University of Science and Technology, Thuwal, 23955-6900, Kingdom of Saudi Arabia.

${ }^{\dagger}$ These authors contribute equally.

*To whom correspondence should be addressed: (J. Ming) jun.ming@kaust.edu.sa or (L. J. Li) lance.li@kaust.edu.sa. 


\section{Experiment}

Materials Preparation: The cathode was composed of $80 \mathrm{wt} \%$ LFP (Laus Deo Company), 10wt \% Super $\mathrm{P}$ carbon and 10wt\% polyvinylidene fluoride (PVDF) binder. In the preparation, the powders were mixed in 1-Methyl-2-pyrrolidinone (NMP) to from a uniform slurry and then casted on $\mathrm{Al}$ foils by doctor blade. After drying in vacuum oven at $80{ }^{\circ} \mathrm{C}$ for $12 \mathrm{~h}$, it is then punched to $Ø 13 \mathrm{~mm}$ circular electrode. The areal mass density of LFP was controlled at a high loading of $5.21 \mathrm{mg} \mathrm{cm}^{-2}$ close to practical application. For the multi-walled carbon nanotubes (MWCNTs)-modified separator, the mixture of MWCNTs (Cnano Technology Company) and PVDF binder with the mass ratio of $9 / 1$ was dispersed into NMP, and then the slurry was casted on the glass fiber separator only one side. The MWCNTs-coated separator was dried first in vacuum oven at $120{ }^{\circ} \mathrm{C}$ for $12 \mathrm{~h}$ and then cut into $\varnothing 18 \mathrm{~mm}$ round discs before use. The electrolyte was prepared as below. Stoichiometric ratio of lithium metal pieces and sulfur powder (to form $0.05 \mathrm{M} \mathrm{Li}_{2} \mathrm{~S}_{8}$ ) were dispersed in $40 \mathrm{~mL} \mathrm{1,3-dioxolane/1,} \mathrm{2-dimethoxyethane}$ (DOL/DME, v/v, 1/1) and stirred at $80{ }^{\circ} \mathrm{C}$ for $48 \mathrm{~h}$. After the reaction, equivalent weight of bis(trifluoromethane) sulfonimide lithium salt (LiTFSI) (Sigma-Aldrich) and $\mathrm{LiNO}_{3}$ were added into the solution, giving rise to the electrolyte of $1 \mathrm{M}$ LiTFSI in DOL/DME containing $0.4 \mathrm{M}$ $\mathrm{LiNO}_{3}$ and $0.05 \mathrm{M} \mathrm{Li}_{2} \mathrm{~S}_{8}$. Note that the chemical composition of $\mathrm{Li}_{2} \mathrm{~S}_{8}$ is described based on the stoichiometric ratio of lithium and sulfur, as those reported in previous literature. ${ }^{\mathrm{S} 1-\mathrm{S} 3}$ The electrolyte without $\mathrm{Li}_{2} \mathrm{~S}_{8}$ was prepared without adding lithium metal and sulfur powder. The commercial electrolyte $1 \mathrm{M} \mathrm{LiPF}_{6}$ in ethylene carbonate/dimethyl carbonate (EC/DMC, 50/50, v/v) was purchased from Sigma-Aldrich.

Electrochemical Measurements: The electrochemical tests were performed using 2032-type cells. The hybrid lithium ion battery has the configuration of LFP |MWCNTs-separator | lithium 
metal, in which the electrolyte of $1 \mathrm{M}$ LiTFSI, $0.4 \mathrm{M} \mathrm{LiNO}_{3}, 0.05 \mathrm{M} \mathrm{Li}_{2} \mathrm{~S}_{8}$ in DOL/DME was used. The amount of the electrolyte is $130 \mu \mathrm{L}$ and the weight of sulfur was calculated based on the amount of $\mathrm{Li}_{2} \mathrm{~S}_{8}$. For comparison, the lithium ion batteries with the $1 \mathrm{M} \mathrm{LiPF}_{6}$ in EC/DMC electrolyte were also tested. The volume ratio of LIB electrolyte : Li-S electrolyte : $\mathrm{Li}_{2} \mathrm{~S}_{8}$-based electrolyte is 1:1:1 (130 $\mu \mathrm{L})$, and the mass ratio of them (i.e., which are weighted by balance) are $170.8 \mathrm{mg}: 138.3 \mathrm{mg}: 139.9 \mathrm{mg}$. The batteries were assembled in Argon-filled glovebox in which the moisture and oxygen were strictly controlled below $0.5 \mathrm{ppm}$. Galvanostatic charge-discharge experiments were carried out by Arbin battery test instrument BT2043 within the voltage window of 1.8-3.6 $\mathrm{V}$ and 1.8-4.0 $\mathrm{V}$ respectively. For the full battery configuration, lithiated graphite was used as anode (i.e., a quantitative amount of lithium deposited on graphite uniformly for the reaction of $\mathrm{Li}_{2} \mathrm{~S}_{\mathrm{x}}$ ), and the cut-off voltage was $1.8-3.75 \mathrm{~V}$. The mass ratio of LFP and graphite is 2.02:1. Cyclic Voltammetry (CV) and electrochemical impedance spectrum (EIS) were recorded for the same cell by the BioLogic VMP3 under the scan rate $0.05-0.25 \mathrm{mV} / \mathrm{s}$.

Characterizations: The interfacial morphology of MWCNTs-separator and LFP electrode were characterized by the field emission scanning electron microscope (FESEM, FEI Quanta 200), operated at $5 \mathrm{kV}$ and $2.5 \mathrm{~mA}$. The elemental distribution of sulfur, carbon, and LFP were analyzed by the energy-dispersive X-ray (EDX) mapping, operated at $10 \mathrm{kV}$ and $6 \mathrm{~mA}$. 


\section{References:}

S1. Lee, D. J.; Agostini, M.; Park, J. W.; Sun, Y. K.; Hassoun J.; Scrosati, B. Progress in Lithium-Sulfur Batteries: The Effective Role of a Polysulfide-Added Electrolyte as Buffer to Prevent Cathode Dissolution. ChemSusChem 2013, 6, 2245-2248.

S1. Agostinia, M.; Lee, D. J.; Scrosatic, B.; Sun, Y. K.; Hassoun, J. Characteristics of $\mathrm{Li}_{2} \mathrm{~S}_{8^{-}}$ Tetraglyme Catholyte in a Semi-Liquid Lithium-Sulfur Battery. J. Power Sources 2014, 265, 14-19.

S2. Agostini, M.; Scrosati, B.; Hassoun, J. An Advanced Lithium-Ion Sulfur Battery for High Energy Storage. Adv. Energy Mater. 2015, 5, 1500481. 

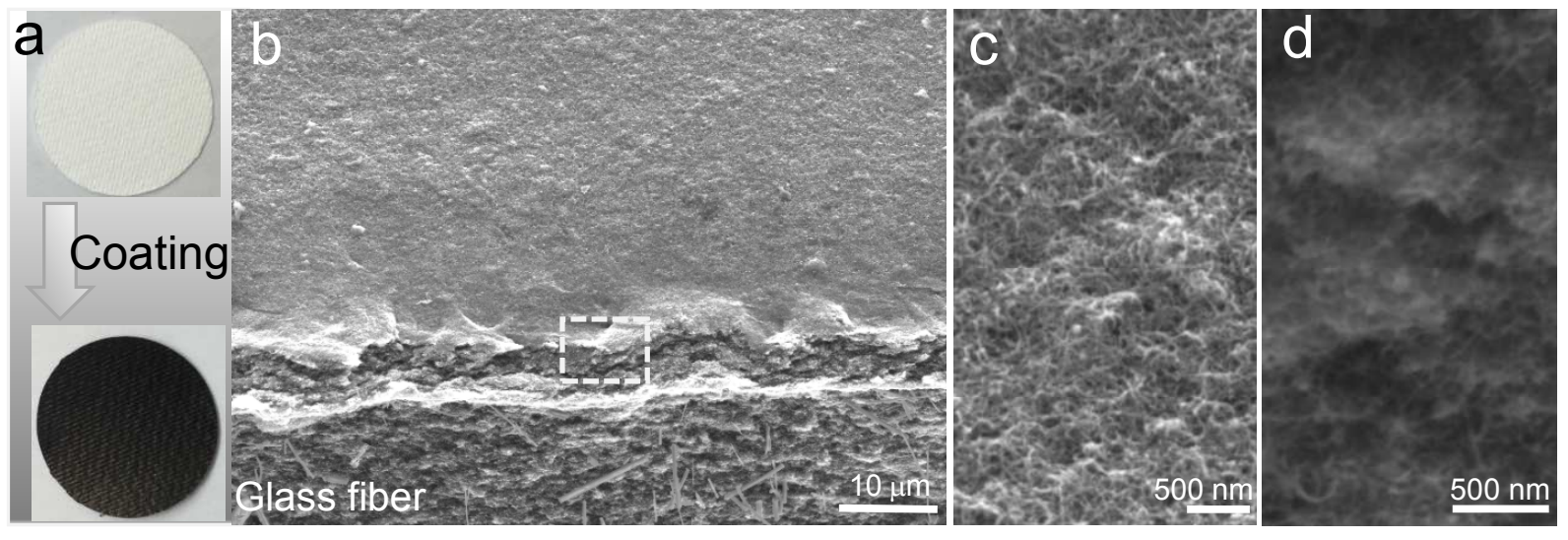

Figure S1. Characterizations of multi-walled carbon nanotube (MWCNTs) modified separator. (a) Digital photo of separator coated by MWCNTs one side. (b) Cross-sectional scanning electron microscope (SEM) images of MWCNTs coated on glass fiber separator. (c) Surficial and (d) sectional morphology in a high magnification as marked in inset of (b). 

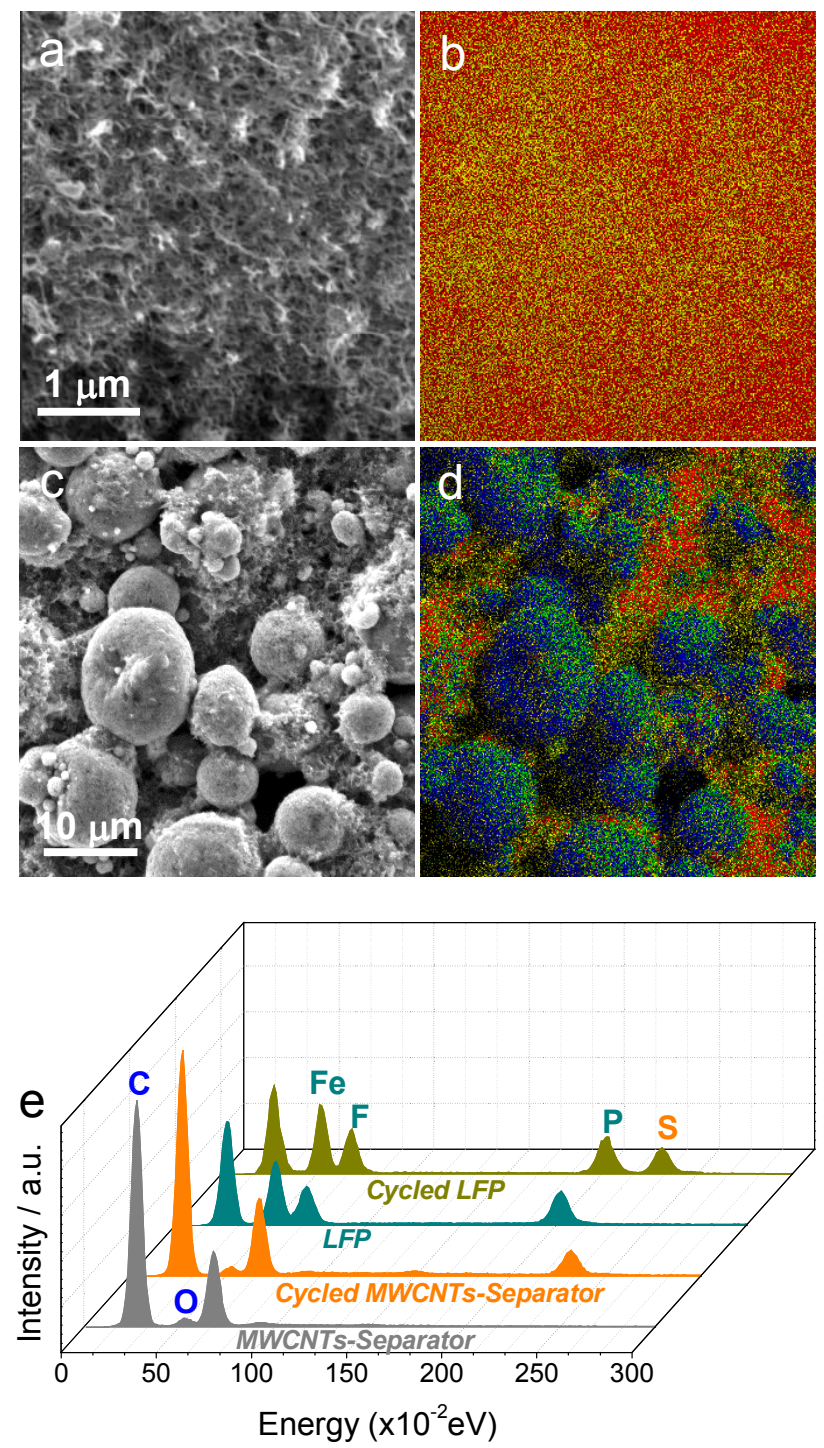

Figure S2. Characterizations of electrode and separator. (a) SEM of cycled MWCNTseparator and relative (b) elemental mapping images. (c) SEM of cycled LFP cathode and (d) elemental mapping images. The colour of red, yellow, and blue-green represent the distribution of carbon, sulfur and LFP, respectively. (e) Energy-dispersive X-ray spectroscopy of battery using $\mathrm{Li}_{2} \mathrm{~S}_{8}$-based electrolyte. The redox reaction of $\mathrm{Li}_{2} \mathrm{~S}_{\mathrm{x}} / \mathrm{Li}_{2} \mathrm{~S}$ mainly occurs on the cathode side, particularly on the MWCNTs because of its high surface area, as confirmed by the dispersion of yellow sulfur. 

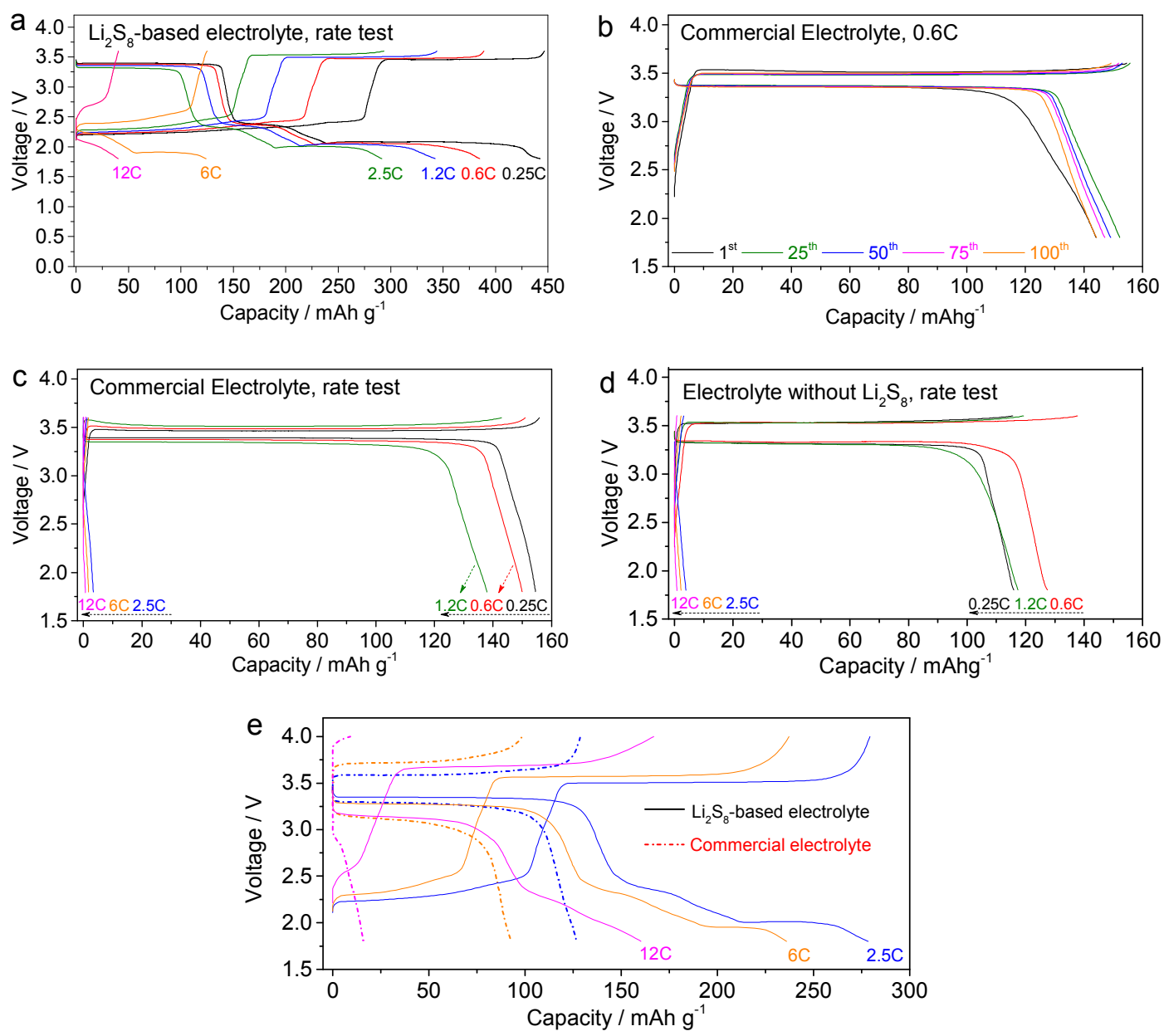

Figure S3. Electrochemical performances of batteries. (a) Rate capability of hybrid battery using $\mathrm{Li}_{2} \mathrm{~S}_{8}$-based electrolyte. (b) Cycle performance of LFP lithium battery under $0.6 \mathrm{C}$ and (c) C-rate test using commercial LIB electrolyte and (d) electrolyte without $\mathrm{Li}_{2} \mathrm{~S}_{8}$. (e) Comparison for batteries using $\mathrm{Li}_{2} \mathrm{~S}_{8}$-based electrolyte (solid line) and commercial LIB electrolyte (dash line) at the high rates of $2.5 \mathrm{C}, 6 \mathrm{C}$, and $12 \mathrm{C}$ charged to $4.0 \mathrm{~V}$. 


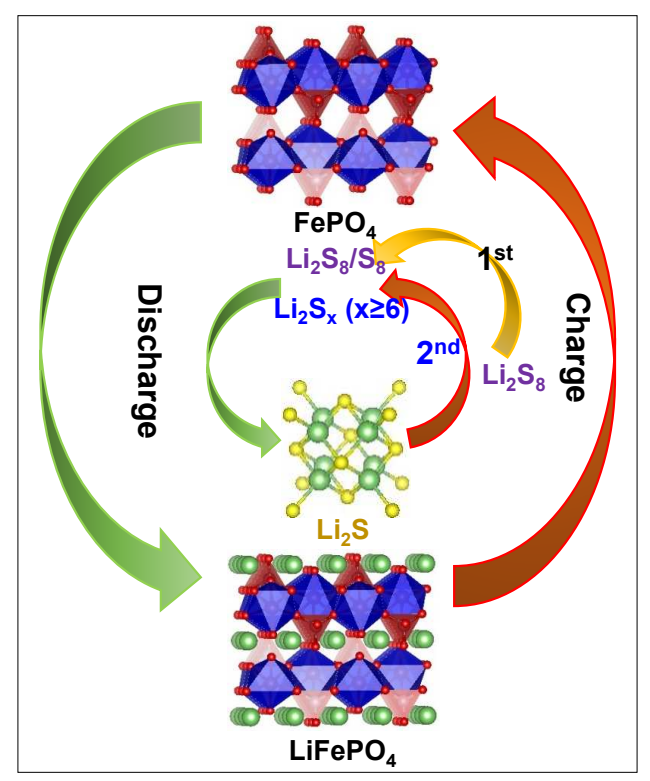

Figure S4. Reaction routine. Proposed reaction mechanism of LFP cathode and $\mathrm{Li}_{2} \mathrm{~S}_{8}$ species in electrolyte during the charge-discharge process. In the first cycle for charge, one part of $\operatorname{Li}_{2} \mathrm{~S}_{8}$ was oxidized to high valence sulfur species (such as sulfur $\left(\mathrm{S}_{8}\right)$ ), probably forming a mixture of $\mathrm{Li}_{2} \mathrm{~S}_{8} / \mathrm{S}_{8}$. Finally, most charged product are long-chain polysulfide from the second cycle and they are abbreviated as $\mathrm{Li}_{2} \mathrm{~S}_{\mathrm{x}}(\mathrm{x} \geq 6)$ for a general description. The increased free $\mathrm{Li}^{+}$and $\mathrm{S}_{\mathrm{x}}{ }^{2-}$ from $\mathrm{Li}_{2} \mathrm{~S}_{\mathrm{x}}$ is helpful for the faster lithium diffusion and then reducing the polarization as discussed. 

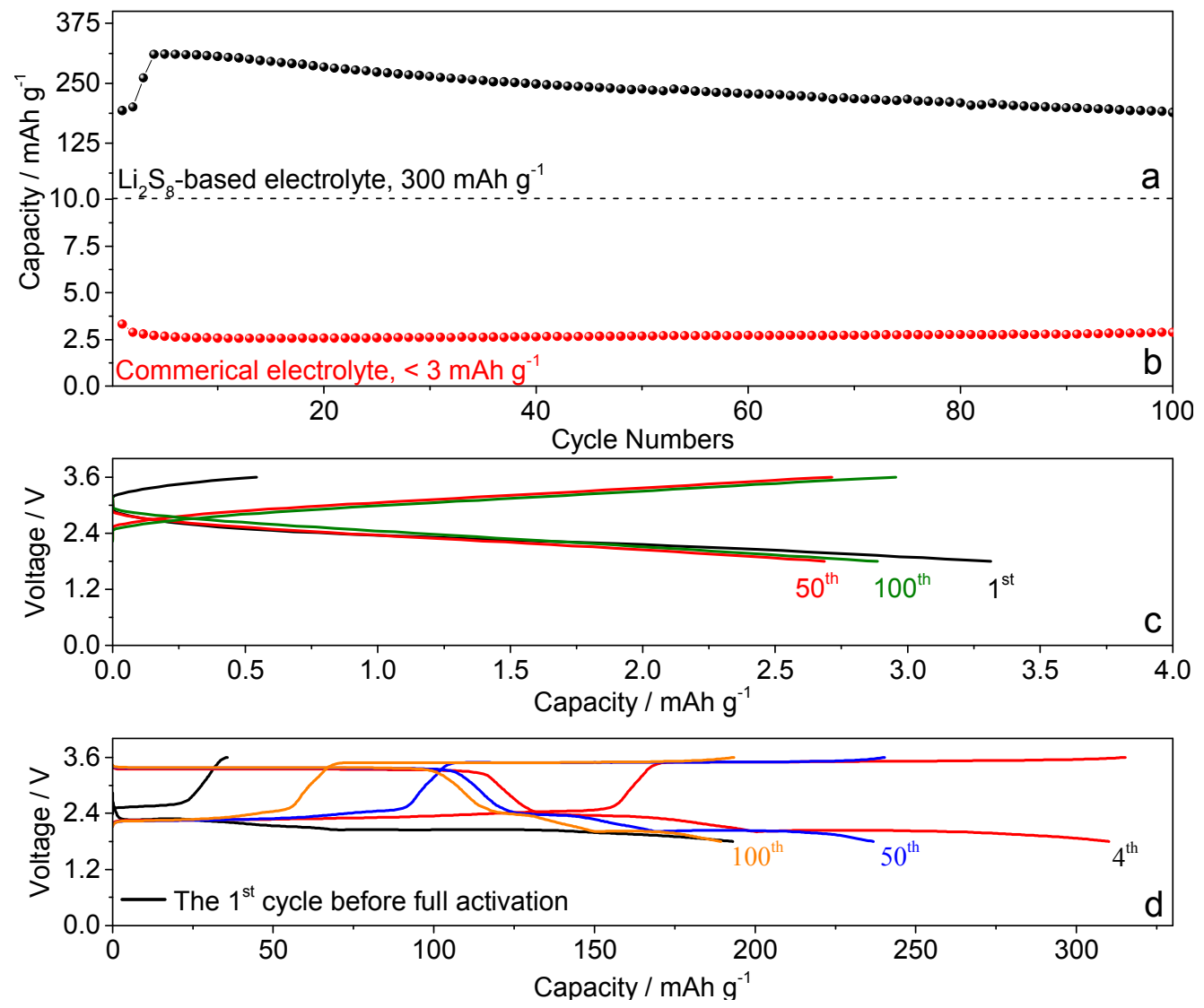

Figure S5. Electrochemical performances of batteries. Comparative cycle performance and typical voltage $v s$. capacity profiles of battery using $(\mathrm{a}, \mathrm{d}) \mathrm{Li}_{2} \mathrm{~S}_{8}$-based and $(\mathrm{b}, \mathrm{c})$ commercial LIB electrolyte. The battery cycled at $2.5 \mathrm{C}$ with the cut-off voltage of $3.6 \mathrm{~V}$. 